\title{
Dominique Desmarchelier - Juliette Rennes (ed.), Usages politiques du genre
}

\section{Elettra Bordino Zorzi}

\section{Q OpenEdition}

10 Journals

\section{Édition électronique}

URL : http://journals.openedition.org/studifrancesi/28337

DOI : $10.4000 /$ studifrancesi.28337

ISSN : 2421-5856

Éditeur

Rosenberg \& Sellier

\section{Édition imprimée}

Date de publication : 31 décembre 2006

Pagination : 655-656

ISSN : 0039-2944

\section{Référence électronique}

Elettra Bordino Zorzi, « Dominique Desmarchelier - Juliette Rennes (ed.), Usages politiques du genre », Studi Francesi [En ligne], 150 (L | III) | 2006, mis en ligne le 30 novembre 2015, consulté le 08 novembre 2020. URL : http://journals.openedition.org/studifrancesi/28337 ; DOI : https://doi.org/10.4000/ studifrancesi.28337

Ce document a été généré automatiquement le 8 novembre 2020.

\section{(c)}

Studi Francesi è distribuita con Licenza Creative Commons Attribuzione - Non commerciale - Non opere derivate 4.0 Internazionale. 


\title{
Dominique Desmarchelier - Juliette Rennes (ed.), Usages politiques du genre
}

\author{
Elettra Bordino Zorzi
}

\section{RÉFÉRENCE}

DOMINIQUE DESMARCHELIER - Juliette RENNES (ed.), Usages politiques du genre, «Mots. Les

langages du politique», n. 78, juillet 2005, pp. 169.

1 Si et comment le genre - et notamment le féminin se démarquant du masculin interagit avec les positionnements et les prises de parole à l'intérieur du champ politique, telle est la question tant sociologique que rhétorique à laquelle tâche de répondre ce numéro de «Mots» (Présentation de Dominique D ESMARCHELIER et Juliette RENNES, pp. 3-5).

2 La première partie, de caractère historique, s'ouvre par l'analyse de Jürgen SIESS (Un discours politique au féminin. Le projet d'olympe de Gouges, pp. 9-21), qui porte sur trois textes politiques d'une intellectuelle engagée œuvrant pendant la Révolution. Chez celle-ci la revendication de l'égalité des sexes se traduit par la subversion des conventions littéraires créées par les hommes et associées respectivement à la lettre publique, à l'épître dédicatoire, à l'avis public. Dans l'article suivant (Édith TAÏ̈B, $L e$ politique et le domestique. L'argumentation d 'Hubertine Auclert sous la Troisième République, pp. 23-36) s'impose une autre ancêtre du féminisme qui, un siècle plus tard, vise à dénoncer par son action publique trois points capitaux du sexisme républicain : l'exploitation de la femme au sein de la famille du fait de la gratuité de son travail domestique, la subordination du féminin au masculin dans la langue française et, dernier aspect mais non des moindres, l'impossibilité d' être élue ou électrice.

La deuxième partie prend, quant à elle, pour objet les avatars contemporains de la problématique du genre dont $L a$ féminisation des noms de métiers et des titres dans la presse 
française (1988-2001) (pp. 37-52) à laquelle s'intéresse Itsuko FuJIMURA. Ce dernier, après avoir remarqué que ce type de féminisation s'accélère brusquement à la suite de la circulaire Jospin de 1998, répertorie les facteurs lexicaux, sémantiques et sociologiques qui influencent la vitesse d'assimilation des divers termes féminins et souligne que, en français, le genre est réticent à adhérer à son référent en raison aussi de son caractère arbitraire. Dans La femme invisible. Sur l'imaginaire du pouvoir politique (pp. 53-64), Grégory DERVILLE et Sylvie PICHON s'interrogent sur les causes de la sous-représentation politique des femmes en France, lesquelles se heurtent non seulement à la mauvaise volonté des hommes, mais encore aux stéréotypes de la féminité, traditionnellement considérée comme peu compatible avec l'exercice du pouvoir. En effet, sur la base d'un corpus de presse, Cécile SouRD (Femmes ou politiques? La représentation des candidates aux élections françaises de 2002 dans la presse hebdomadaire, pp. 65-77) remarque un clivage dans les représentations joumalistiques concernant les acteurs et les actrices du champ politique: le portrait de ces dernières semble ne pas pouvoir se passer d'un ancrage au genre sexuel, qu'elles apparaissent comme foncièrement féminines ou, ce qui revient au même, comme masculines, car le discours évoque immanquablement leur apparence physique ainsi que la sphère privée de leurs affects et relations intimes. Il n'en va pas autrement pour Marine Le Pen (Julie BoudiLlon, Une femme d'extrême droite dans les médias. Le cas de Marine Le Pen, pp. 79-89), dont l'image médiatique, hybride et parfois outrageante, se construit d'un côté en fonction de l'héritage «viril» et populiste du père, de l'autre en rapport avec une féminité sentimentale et comportementale qui la qualifie de "pasionaria» et de "racoleuse». Gilles GAUTHIER (Une caractérisation du raisonnement à l'épreuve d'un corpus d'éditoriaux, pp. 93-103) se penche en revanche sur les spécificités argumentatives qui distingueraient les raisonnement des femmes de ceux des hommes. Le premier tri d'un groupe d'éditoriaux québécois récents montre que, à l'encontre d'un lieu commun assez répandu, le deuxième sexe recourt aux déductions et aux inductions plus que son pendant masculin qui, lui, utilise plus souvent l'analogie. Encore une étude de corpus dans l'essai de Serge VASsY, intitulé Ethos de femmes ministres. Recherche d'indices quantifiables (pp. 105-114), mais cette fois les considérations d'ordre qualitatif cèdent le pas à une élaboration quantitative des données où se dessinent quelques tendances générales: par le suremploi de formes foncièrement subjectives - les pronoms je/on/nous, les verbes croire, souhaiter, avoir envie - les femmes ministres trahissent un investissement émotionnel plus fort que leurs collègues mâles.

4 Après une analyse sociologique du majoritaire social, la rubrique conclusive Des mots en politique accueille une réflexion lexicographique de Michel TOURNIER, De Barbare à Babel, des sons qui bredouillent et excluent (pp. 131-142) où, dans la foulée de Pierre Guiraud, la séquence phonique $\mathrm{BL} / \mathrm{BR}$ est envisagée comme la matrice onomatopéique originale de nombreux vocables exprimant le bruit et la confusion sonore ou bien linguistique comme - exemples emblématiques - barbare et Babel. 